ELORE (ISSN 1456-3010), vol. 18 - 2/2011.

Julkaisija: Suomen Kansantietouden Tutkijain Seura ry.

[http://www.elore.fi/arkisto/2_11/koski.pdf]

\title{
AJANKOHTAISTA
}

\section{KIELI JA FOLKLORE - YHTÄ JA TOISTA MAATA}

\section{$\underline{\text { Kaarina Koski }}$}

Finno-ugric contribution to international research on folklore, myth and cultural identity. Fifth International Symposium on Finno-Ugric Languages in Groningen.

Groningenin yliopisto 7.-9. 6. 2011.

Hollannin Groningenin yliopistossa sijaitsee Benelux-maiden ainoa suomalais-ugrilaisten kielten ja kulttuurien laitos. Pieni mutta pippurinen yksikkö järjestää joka viides vuosi kansainvälisen symposiumin. Kesäkuussa 2011 pidetty symposiumi oli lajissaan viides ja sen teemana oli suomalais-ugrilainen panos folkloren, myyttien ja kansallisten identiteettien tutkimuksessa. Tapahtuma houkutteli paikalle viitisenkymmentä kielen, folkloren ja kirjallisuuden tutkijaa etupäässä Hollannista, Saksasta, Unkarista, Virosta, Suomesta ja Venäjältä. Esitelmissä tärkeimmiksi aihepiireiksi nousivat etniset identiteetit, mytologia ja mytologinen sanasto, Kalevalan ja Kalevipoegin tulkinnat ja reseptiot sekä folkloren arvo kielentutkimuksen lähteenä. ${ }^{1}$

Kieltä ja folklorea tarkasteleva symposiumi voisi parhaimmillaan olla antoisa keskustelufoorumi folkloristien ja kielentutkijoiden välillä. Vuorovaikutukseen oli luotu edellytyksiä, sillä suuri osa työryhmistä kokosi yhteen eri aloja edustavista esityksistä. Groningenin suomalais-ugrilaisen laitoksen johtaja ja symposiumin pääorganisoija Cornelius Hasselblatt perusteli teeman valintaa: "Folklorea on kaikkialla. Mutta suomalais-ugrilaisista kansoista monet ovat pieniä, ja niiden kieltä tutkittaessa käytettävissä on vain folkloristista aineistoa. Myös kolme suomalais-ugrilaista EU-maata on rakentanut identiteettiään folkloren varaan." Monille symposiumissa puhuneille kielentutkijoille nämä lauseet merkitsivät sitä, että folkloreaineistot ovat ensisijaisesti välineitä kielen ja etnisen identiteetin tutkimiseen. Osa heistä lähestyi folklorea pelkkänä kielenaineksena tai lähdetekstinä ilman kiinnostusta keskusteluun folkloresta sinänsä. Toisissa esitelmissä taas folkloresta ja kirjallisuudesta puhuttiin ilman kieleen liittyviä näkökulmia. Kielen- ja kulttuurintutkimuksen näkökulmat eivät siis kaikilta osin kohdanneet. Yhteinen kosketuspinta tutkijoiden välillä ei automaattisesti synny pelkän yhteisen aineiston ja tutkimuskohteen suomalais-ugrilaisuuden perusteella;

1 Kiitän helsinkiläisiä folkloristikollegoita Karina Lukinia, Eila Stepanovaa ja Frogia näkökulmista sekä tiedoista myös rinnakkaisissa sessioissa kuultujen esitelmien osalta. 
Kaarina Koski: Kieli ja folklore - yhtä ja toista maata

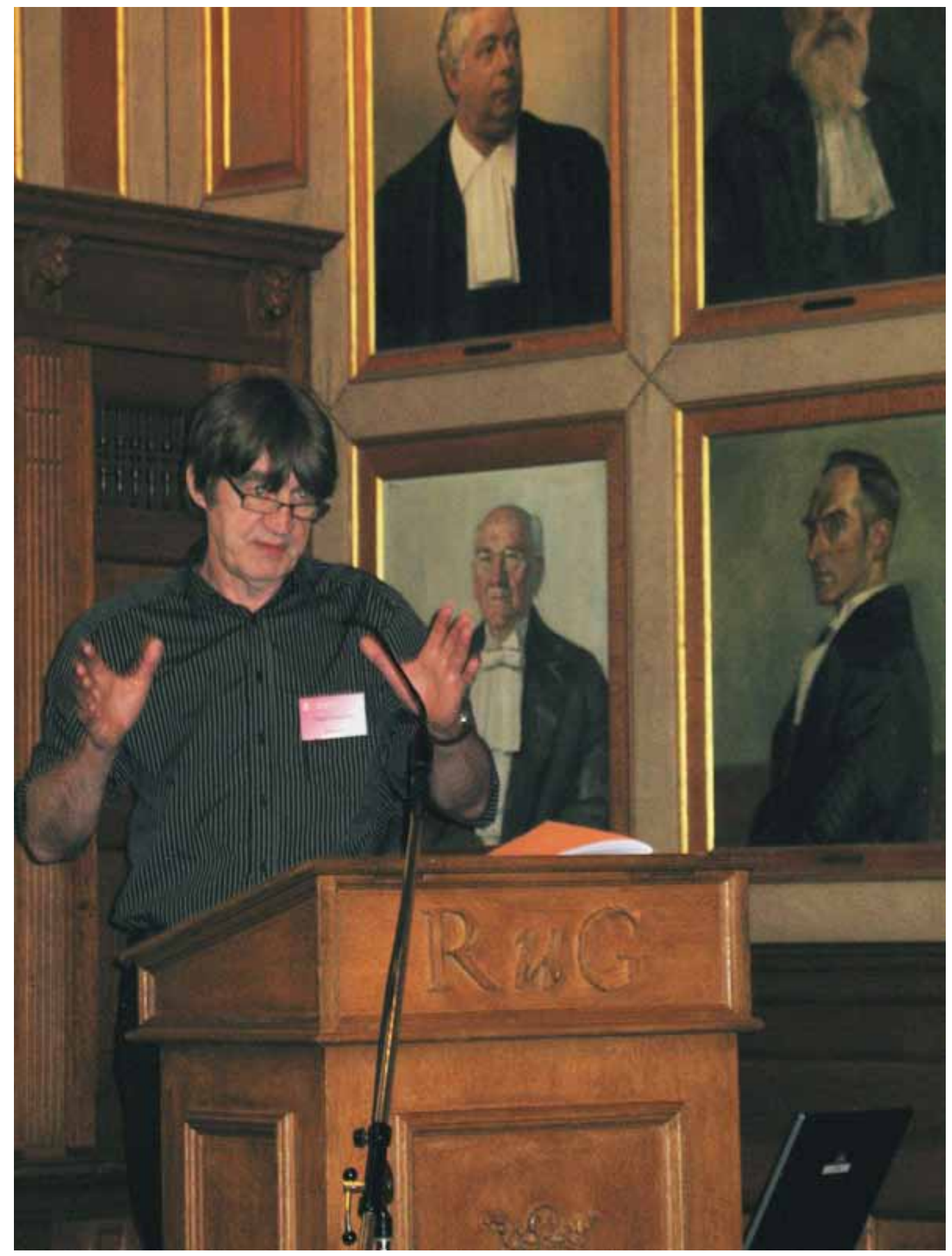

Seppo Knuuttila Itä-Suomen yliopistosta puhui keynote-luennossaan myyttien visualisoinnista. Groningenin yliopiston Senaattisalin hieno muotokuvagalleria sai muuntautua kansainvälisen Kalevala-taiteen näyttämöksi. Kuva: Eila Stepanova. 
tärkeitä ovat myös aineistolle esitetyt kysymykset ja niistä tehdyt päätelmät. Eroista huolimatta loogisesti esitetyt ja hyvin perustellut tutkimustulokset vieraastakin aiheesta olivat innostavia ja jopa viihdyttäviä.

Folkloristien panos oli tehty symposiumissa näkyväksi: kaikki kolme plenaristia, Mihály Hoppál (Eötvös Loránd -yliopisto, Budapest), Seppo Knuuttila (Itä-Suomen yliopisto, Joensuu) ja Ülo Valk (Tarton yliopisto), ovat folkloristeja. Samalla he edustivat tasapuolisesti Hasselblattin mainitsemia "kolmea suomalais-ugrilaista EU-maata", joissa sekä suomalais-ugrilaisten kielien että folkloren tutkimus ovat vahvoilla.

\section{FOLKLORE KIELENTUTKIMUKSEN JA KIELI FOLKLORISTIIKAN LÄHTEENÄ}

Yksi suosituista esitelmissä käsitellyistä kysymyksistä oli, soveltuvatko folkloreaineistot kielentutkimuksen lähteeksi. Esimerkiksi Elena Markus (Tarton yliopisto) ja Fedor Rozhanskiy (Venäjän Tiedeakatemian Kielitieteellinen Instituutti, Pietari) olivat tutkineet eri kerääjien tallentamia vatjalaisitkuja Aili Nenolan toimittamasta Inkerin itkwvirret -kokoelmasta (Nenola 2002). He osoittivat laskennallisella menetelmällä muutamien kielipiirteiden kuten minä-pronominin muotojen perusteella, että kirjoitusasun hajonta sekä kerääjien välillä että kunkin kerääjän eri säkeissä on liian laajaa, jotta aineisto voisi soveltua kielentutkimuksen lähteeksi. Tällainen kiistaton tulos saattaa olla merkittävä omassa kontekstissaan - ehkäpä kysymys folkloretekstien validiudesta on päivänpolttava pienten kielten tutkimuksessa. Mutta suomalainen folkloristi jäi odottavaan "entä sitten” -tilaan. Eikö yritetty selvittää, kuka kerääjistä oli ehkä toistanut kuulemansa uskollisimmin? Eikö tarkasteltu kerääjien taustoja ja päätelty, että ainakin yksi heistä osoitti tallenteensa suomalaiselle yleisölle ja muotoili tekstiä ehkä poliittisistakin syistä suomen kaltaiseksi? Eikö eroteltu lausekonteksteja minun/miun/miu-hajonnan takana? Entä millaista aineistoa vatjan tutkimiseksi saa käyttää? Tämä esitelmä ei ollut ainoa, joka herätti ainakin folkloristeissa paljon kysymyksiä mutta vastasi niistä vain siihen vähiten kiinnostavaan.

Folkloristien ja fennougristien välinen yhteistyö voisi muodostua hedelmälliseksi esimerkiksi mytologisen sanaston tutkimuksessa. Suomalais-ugrilaisten kielten professori Janne Saarikivi (Helsingin yliopisto) oli tarttunut Mikael Agricolan Psalttarin esipuheen jumalten luettelossa mainittuihin nimiin etymologiselta kannalta. Helsingin yliopistoa edustavista folkloristeista Frog tutki Ilmarisen ja siihen muilla kansoilla liittyvien jumaluuksien välisiä suhteita ja Kaarina Koski esitteli Agricolankin teksteissä esiintyneitä yliluonnollista olentoa merkitseviä sanoja ja niiden merkitysyhteyksiä syöpäläisiin ja epäsosiaaliseen käytökseen. Käsittelytavoissa oli selvä ero: folkloristeja kiinnosti se, mihin ja miten sanoja on käytetty, etymologia taas se, mistä sanat ovat tulleet. Saarikivi esitti toiveen, että kielitieteelliset ja folkloristiset näkökulmat voisivat kohdata enemmän mytologian tutkimuksessa. Yksi kohtaamistapa olisi, että folkloristit tarttuisivat jälleen hanakammin mytologisiin aiheisiin ja ottaisivat huomioon uusimman etymologisen tutkimuksen. Kielitieteen puolella etymologia on huomioinut vain vähän 
nimiä - jumalien nimet mukaan lukien. Uudempi tutkimustieto näiden nimien käytöstä folkloressa voisi edistää asiaa. Saarikivi osoittaa vääriksi useita esimerkiksi Martti Haavion (Haavio 1959) jumalatulkintojen pohjana olevia etymologioita. Lisäksi hän on osoittanut vääräksi germaanisiin kieliin perustuvan etymologian, joka yhdistää suomen pyhä-sanan rajan merkitykseen, ja harmittelee rajan merkitykseen perustuvien viimeaikaisten pyhä-tulkintojen runsautta (ks. Saarikivi 2007). Onko vanhasuomalaiseen pyhään kohdistunut tutkimus mennyt harhaan väärän etymologian ohjaamana? Entä mikä on etymologian arvo suhteessa laajaan synkroniseen kieli- ja folkloreaineistoon? Kuinka paljon alkuperä vaikuttaa sanan myöhempään käyttöön ja merkityksiin sekä niiden tutkimiseen? Parhaimmillaan diakroninen ja synkroninen näkökulma voitaisiin yhdistää. Monitieteinen yhteistyö voisi olla avain sen onnistumiseen.

\section{IDENTITEETIT JA SYMBOLIT}

Monitieteisyys voisi olla hyväksi myös identiteettien tutkimisessa. Useissa esitelmissä identiteetin katsottiin itsestään selvästi perustuvan kansallisuuteen ja kieleen. Tätä näkökulmaa kuitenkin myös kritisoitiin. Kuten Eva Toulouze (Pariisin yliopisto / Tarton yliopisto) osuvasti huomautti, esimerkiksi metsänenetsien, hantien ja selkupien parissa identiteetti rakentuu ensisijaisemmin elinkeinojen ja elämäntavan pohjalta. Perinteistä elinkeinoa harjoittava väestö kokee kielirajoista riippumatta enemmän yhteenkuuluvuutta toisiinsa kuin kaupungeissa asuviin maanmiehiinsä. Kun kielen lisäksi tutkitaan myös jotakin muuta osa-aluetta kuten identiteettiä, yhteisöä tai mytologiaa, myös asiantuntemuksen on katettava enemmän kuin kieli.

Varsin kiinnostava oli Natalia Glukhovan (Joshkar-Ola) esittelemä marilaisen identiteetin psykologisten komponenttien rekonstruktio marinkielisten folkloretekstien pohjalta. Glukhova määritteli etnisen identiteetin ajattelutapojen ja tunnereaktioiden pohjalta systeemiksi, jonka osa-alueita ovat kuvasto, yhteiset symbolit ja arvot. Hän oli tehnyt jo edesmenneen puolisonsa Vladimir Glukhovin kanssa tuhansiin teksteihin perustuvan, laskennallisen analyysin eri perinnelajeissa esiintyvistä mielikuvista, symboleista ja niihin liittyvistä emotionaalisista reaktioista sekä ajan ja tilan hahmotustavoista. Tutkimus selvitti - Glukhovan mukaan tyhjentävästi - perinteiseen mari-identiteettiin kuuluvat psyykkiset reaktiotavat, arvot ja kuvaston. Aikaa tämän suurtyön esittelyyn olisi ilmeisesti tarvittu puolen tunnin sijasta noin viikko; tällä kertaa kuulijoiden oli tyydyttävä uskomaan, että heidän tiedustelemansa näkökulmat oli kaikki jo otettu tutkimuksessa huomioon, mutta niitä ei vain ehditty esitellä.

Kansalliset erot mielikuvien ja motiivien yleisyydessä tulivat aivan toisella tavalla esille Jonathan Roperin (Tarton yliopisto) esityksessä, jossa hän vertaili germaanisia ja virolaisia eeppisiä runoja. Rinnastuksen varsinainen tavoite oli tuoda toistensa yhteyteen näiden eri runostojen tutkimustraditioita ja metodeita. Maininta siitä, että englantilaisen runouden käytetyintä sanastoa ovat matka, taistelu ja tuli ja virolaisen taas neito, äiti ja kihlaus, oli sivujuonne esityksessä, joka tarkasteli synonyymien asemaa allitteratiivisissa säkeissä. Allitteraatiivisiin eli alkusoinnullisiin säkeisiin tarvitaan keskeisimmistä runoissa käytetyistä sanoista eri kirjaimilla alkavia synonyymeja. Roper 
esitti germaaniepiikan tutkimukseen nojaten, että asemaltaan keskeisimmät symbolit esiintyvät kaikkein useimmin alkusoinnullisina omassa säkeessään. Tällainen järjestelmä generoi säkeiden tarpeisiin sopivia synonyymisia ilmaisuja tärkeimmistä symboleista. Roperin selkeä, perusteltu ja metodologisesti antoisa esitys sivisti ja elähdytti myös proosaperinteen tutkijaa. Jos tutkisin runoja, haluaisin tehdä juuri noin!

\section{KALEVALA JA KALEVIPOEG}

Groningenin fennougristiikalle on ominaista, että se kattaa kielen lisäksi kiinnostuksen kansallisiin historioihin, folkloreen, kirjallisuuteen ja taiteeseen. Yksikön johtaja Cornelius Hasselblatt tarkasteli esityksessään Kalevipoeg-eepoksen kirjallisia versioita alkaen 1800-luvulta ja päätyen Kalevipoeg-vaikutteisiin amerikkalaisiin fantasiakirjoihin ja niiden käännöksiin 1980-luvulta. Viimeksi mainituissa saksantaja ei enää tunnistanut oikeita paikannimiä vaan on korvannut ne mielikuvituksellisilla. Yhteys alkuperäiseen katkeaa, vaikka sisältö on edelleen tunnistettavissa. Teoreettisena taustana Hasselblatt käytti virolaisen Walter Andersonin näkemystä folkloren variaation itsekorjaavuudesta vuodelta 1923. Olipa tämä vanha teoria paikallaan tai ei, idea on selvä: myös painetut kirjalliset teokset varioivat ja esittävät saman aineksen uutena performanssina kuten suullinenkin folklore.

Kalevalan osalta erityisesti Kullervo nousi käsittelyn kohteeksi. Seppo Knuuttila piti plenaariluentona yleisesityksen Kalevala-aiheisesta taiteesta, erityisesti nykytaiteesta. Pohjana olivat Kalevalaseuran rahoittamat uuden Kalevala-taiteen hankkeet Suomessa ja ulkomailla. Kuvataiteen alueella jatkoi Groningenin yliopistoa ja isäntälaitosta edustava Adriaan van der Hoeven, joka keskittyi Kullervoon ja eri aikakausina syntyneiden tekstuaalisten ja visuaalisten Kullervo-kuvien kulttuurisiin ja poliittisiin kytkentöihin. Myyttispohjaisen kuvaston visualisoinnilla on korostettu milloin Suomen yhteyttä eurooppalaiseen kulttuuriperintöön, milloin kansallista omaleimaisuutta. Kansallisromanttinen Kullervo kohotettuine nyrkkeineen toimi poliittisesti kansallisen vastarinnan symbolina; myöhemmin nyrkki tuli Kullervon omaksi, toistuvaksi tavaramerkiksi. Nykytaiteen Kullervoista ideologia on van der Hoevenin mukaan riisuttu: teokset kuvastavat taiteilijoiden henkilökohtaisia tavoitteita ja näkemyksiä. Odotamme kiinnostuneina, miten tulevaisuuden taidehistoria tulkitsee tilannetta. van der Hoevenin esittämä kuva-aineisto oli ilahduttavan laajaa ja monipuolista. Me lapsenmieliset odotimme innokkaina myös Mauri Kunnaksen Koirien Kalevalan Kullervoa - emmekä turhaan! Kiinnostavan näkökulman Kullervoon tarjosi myös Groningenista Tukholman yliopistoon siirtynyt Merlijn de Smit. Hän sovelsi Kullervoon René Girardin ajatusta myyttisestä syntipukista, jonka uhraamisen myötä pyritään saamaan hallintaan yhteisössä kytevä viha. de Smitin käsittelyssä Kullervon tarina näyttäytyy syntipukin uhraamisyrityksen epäonnistumisena. Yhteisöllistä puhdistumista ja vihan kanavointia ei tapahdu, ja seurauksena on vain laajempi tragedioiden ketju. Girardilainen tulkinta oli kerrassaan raikas ja herätti taas kerran synkeitä ajatuksia mytologiamme tarjoamista ongelmanratkaisumalleista. 


\section{TutTua ja OUTOA}

Virolaiskollegoitten tutkimukset olivat kautta linjan kiinnostavaa kuunneltavaa. Uskomusperinteen osalta näkökulmat ovat tutunoloisesti samoja kuin Suomessa. Madis Arukask (Tarton yliopisto) puhui rajan keskeisyydestä vepsäläisessä kansanuskossa ja etenkin suhteessa metsään. Hän esitteli kenttätyöaineistoaan, jossa kansanuskoon kietoutuu runsaasti ortodoksista ainesta, ja herätti myös runsasta keskustelua paimenen asemasta ikään kuin metsän sulhasena, jota koskivat ankarat seksuaalitabut. Ülo Valkin plenaariluento käsitteli tarinoiden suhdetta aikansa sosiaalisiin oloihin. Valk nosti esille folkloren suullis-kirjallisen luonteen ja tarkasteli tarinoiden sekä niiden kuvaamien aihepiirien esiintymistä 1800-luvun sanomalehdissä. Parhaimmillaan aineisto muistutti nykytarinoita, esimerkiksi kun Venäjän koleraepidemia synnytti huhuja koleran tahallisesta levittämisestä. Tarina kertoi, kuinka kerjäläiseksi pukeutunut muukalainen laittoi outoa jauhetta perheen puuroon, mutta jäi kiinni.

Groningenin symposiumin esitelmiä kuunnellessa suomalaisjoukkueen tunnelmat vaihtelivat kiinnostuksesta ja oivalluksista hämmennykseen ja turhautumiseen. Tieteellisen annin epätasaisuus oli omiaan kirvoittamaan antoisaa keskustelua ruoka- ja kahvitauoilla, jotka olivat kerrankin riittävän pitkiä. Kun skaala oli laaja, ohjelman helmiä osasi arvostaa. Ja huonoiksikin arvioimistamme esitelmistä saattoi oppia jotakin - ellei muuta niin edes sen, millaista tiedettä muualla tehdään. Kokonaisuutena symposiumi oli rennosti keskusteleva, iloinen ja hyväntuulinen ikkuna monenmoiseen tutkimukseen. Hämmennyksen hetkien ohella se opetti arvostamaan monitieteisiä lähestymistapoja sekä ennen kaikkea loogisesti jäsenneltyjä hyviä esityksiä, olipa aihe mikä tahansa.

\section{KirJallisuUs}

HAAVIO, MARTTI 1959: Karjalan jumalat. Uskontotieteellinen tutkimus. Porvoo: WSOY. NENOLA, AILI 2002: Inkerin itkuvirret. Ingrian Laments. Helsinki: SKS.

SAARIKIVI, JANNE 2007: Uusia vanhoja sanoja. - Jussi Ylikoski ja Ante Aikio (toim.), Sámit, sánit, sátnebámit: riepmocála Pekka Sammallabtii miessemánu 21. beaivve 2007. Helsinki: Suomalais-ugrilainen seura.

Filosofian tohtori Kaarina Koski on folkloristi ja uskomusperinteen tutkija Helsingin yliopistossa. 